\title{
A Preliminary Comparison of the Vasculature of the Spiral Valve in the Yellow Stingray, Urobatis jamaicensis, and the North American Paddlefish, Polyodon spathula
}

\author{
K.M. Maroni*, R.E. Spieler*, R.L. Sherman ** \\ * Oceanographic Center, Nova Southeastern University, Dania Beach, FL 33004 \\ ** Farquhar College of Arts and Sciences, Nova Southeastern University, Fort Lauderdale, FL \\ 33314
}

The spiral valve intestine is found in several primitive fish groups including Elasmobranchii and Chondrostei. The spiral valve functions to increase the surface area of the intestine and allow for greater absorption of nutrients from digested food. This study examines structural differences in the arrangement of the vasculature of the spiral valve in two representatives of these groups.

Utilizing Mercox ${ }^{\circledR}$ corrosion casts and light microscopy, we observed similarities and dissimilarities between the spiral valve vasculature of the yellow stingray, Urobatis jamaicensis, and the North American paddlefish, Polyodon spathula. The anterior mesenteric artery branches off the dorsal aorta posterior to the gill region in both species and runs posteriorly towards the spiral valve ${ }^{[1]}$. At the spiral valve, the anterior mesenteric artery (AMA) in U. jamaicensis lies on top of the posterior intestinal vein (PIV) (Fig. 1A) whereas in P. spathula, the anterior mesenteric artery is flanked by the posterior intestinal vein and its branches (Fig. 1B). In U. jamaicensis, vessels branch from the anterior mesenteric artery and proceed under the posterior intestinal vein. However, in P. spathula, the vessels which branch from the anterior mesenteric artery run parallel and continue to be flanked by the branches of the posterior intestinal vein. In both species, the anterior mesenteric artery and posterior intestinal vein give off numerous annular branches which anastomose with each other on the opposite side of the spiral valve (Fig. 2). These annular rings may correspond with each turn of the spiral valve.

Although similar in their basic design, $U$. jamaicensis has 12-14 turns in the spiral valve and $P$. spathula has 5-7 turns ${ }^{[1,2]}$. The significance of the differences in position of the anterior mesenteric artery and posterior intestinal vein in $U$. jamaicensis and $P$. spathula are unclear at this time. Possibly, because $U$. jamaicensis has a greater number of turns of the spiral valve and annular rings per $\mathrm{cm}$ of tissue, the arrangement of the anterior mesenteric artery branches lying under, rather than beside, the posterior intestinal vein branches in $U$. jamaicensis may serve to utilize the space more efficiently.

\section{References}

[1] J.F. Daniel, The Elasmobranch Fishes, $2^{\text {nd }}$ ed., University of California Press, Berkeley, 1928. [2] M. Jollie, Chordate Morphology, Huntington, New York, 1973.

Acknowledgement: The assistance of A.T. St. Gelais with photography is greatly appreciated. 

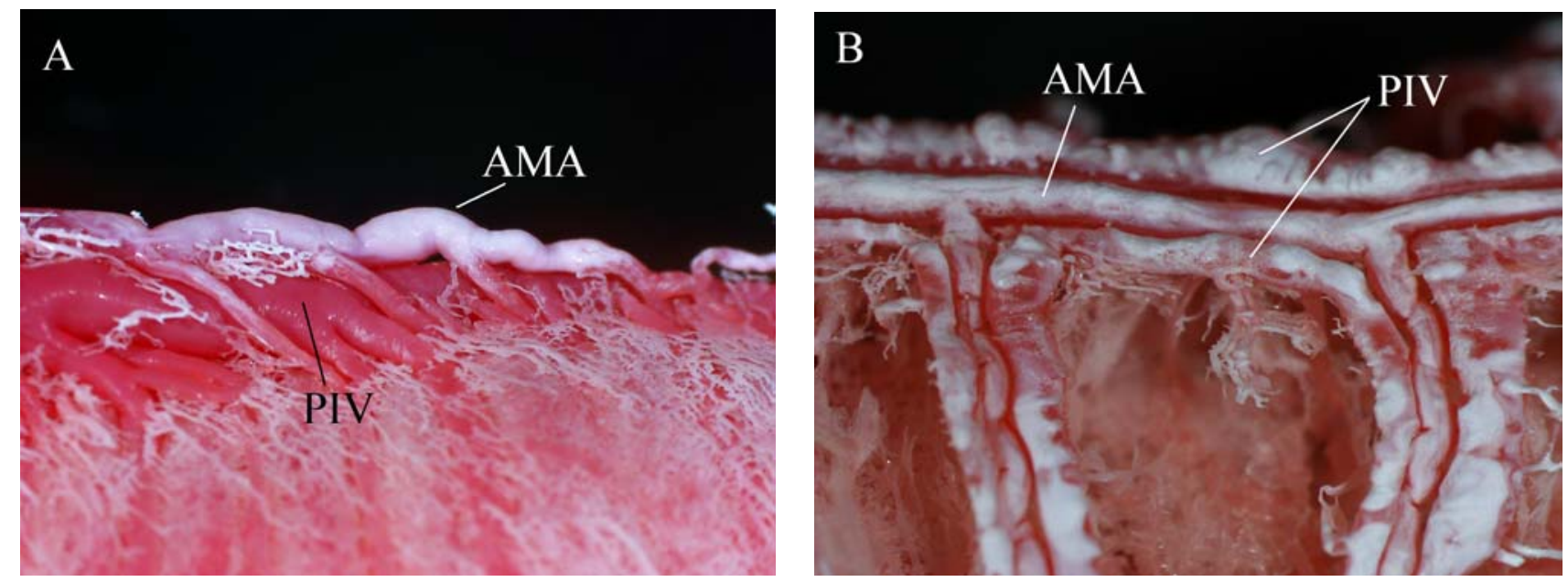

FIG. 1. Example of anterior mesenteric artery (AMA) and posterior intestinal vein (PIV) positioning on the spiral valve in Urobatis jamaicensis (A) and Polyodon spathula (B).
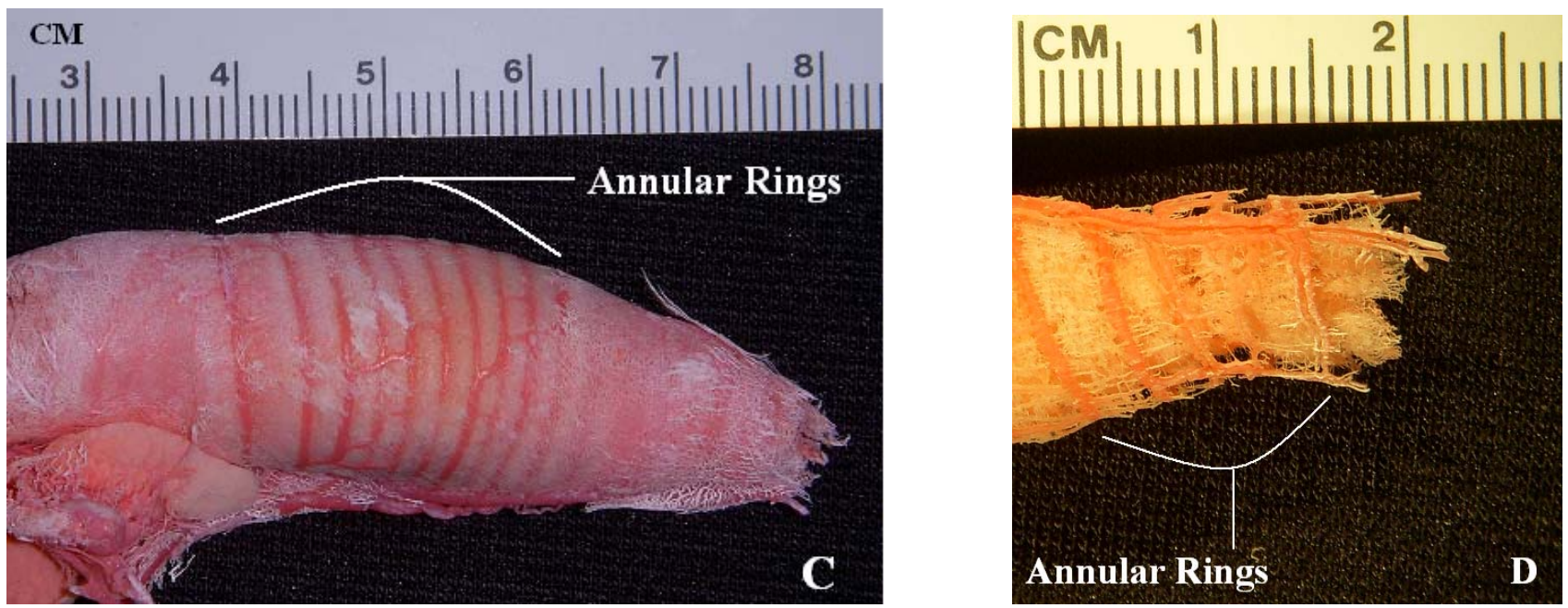

FIG. 2. Example of the annular rings of the spiral valve of Urobatis jamaicensis (C) and Polyodon spathula $(\mathrm{D})$. 